\title{
Evaluación de la concentración de nitratos, calidad microbiológica y funcional en lechuga (Lactuca sativa L.) cultivadas en los sistemas acuapónico e hidropónico
}

\author{
evaluation of nitrate concentration, microbiological and functional quality in lettuce \\ (Lactuca sativa L.) cultivated in aquaponic and hydroponic systems
}

\author{
Edgar Wilber Alcarraz Quispe ${ }^{1,2^{*}}$, María Luisa Tapia Figueras ${ }^{1}$, Andrés Bustamante Pezoa $^{1}$, Olivia Tapia Laguna ${ }^{3}$ Jurij \\ Wacyk Gonzales ${ }^{3}$, Víctor Hugo Escalona Contreras ${ }^{1}$ \\ * Autor de correspondencia
}

\begin{abstract}
Resumen
La Acuaponía es la integración de la acuicultura e hidroponía, corresponde a un sistema de recirculación acuícola donde los desechos producidos por organismos acuáticos se convierten en los nutrientes necesarios para el crecimiento de plantas por medio de la acción bacteriana. Este sistema es de bajo consumo hídrico e impacto ambiental en comparación a los sistemas hidropónicos y acuícolas tradicionales. En el presente trabajo se evaluó el rendimiento, concentración de nitrato, calidad microbiológica y funcional en lechugas (Lactuca sativa L.) cultivadas en dos sistemas de producción: acuapónico e hidropónico. Al mismo tiempo se evaluó la ganancia de masa fresca y el factor de conversión alimentaria (FCA) de trucha arco iris (Oncorhynchus mykiss). Las lechugas se cultivaron en un sistema acuapónico con residuos de los peces y en un sistema hidropónico con solución nutritiva (Hoagland II-modificada) durante 21 días. Al término de este período se obtuvieron lechugas con un tamaño de 8 a $12 \mathrm{~cm}$. El rendimiento de masa fresca de lechugas acuapónicas fue un 6,73\% superior al de lechugas hidropónicas. Por otra parte, en lechugas acuapónicas se determinó una concentración menor de nitratos respecto a lechugas hidropónicas. Las lechugas cultivadas en ambos sistemas no presentaron diferencias significativas en su calidad microbiológica y funcional. El sistema acuapónico se inició con truchas arco iris de una masa fresca promedio de 27,1 $\pm 0,8 \mathrm{~g}$, y durante el experimento los peces incrementaron 13,6 g, obteniéndose un FCA de 0,74. Estos resultados indicarían que el sistema acuapónico utilizado es una alternativa sustentable para la producción de lechugas de alta calidad, considerando su buen rendimiento, menor concentración de nitratos, similar calidad microbiológica y funcional respecto a los sistemas hidropónicos, que permite a su vez el cultivo simultáneo de peces con un buen factor de conversión alimentaria.
\end{abstract}

Palabras clave: Acuaponía; hidroponía; inocuidad alimentaria; factor de conversión alimenticia; trucha arco iris.

\begin{abstract}
Aquaponics is the integration of aquaculture and hydroponics and generally corresponds to a recirculating aquaculture system where the waste produced by aquatic organisms becomes nutrients through bacterial action for plant growth. Water consumption as well as the environmental impact are lower in this system compared to traditional hydroponic and aquaculture modalities. The present study evaluated the yield, nitrate concentration, microbiological and functional quality of lettuce (Lactuca sativa L.) grown in two production systems: aquaponics and hydroponics. At the same time, fresh mass gain and feed conversion ratio (FCR) of rainbow trout (Oncorhynchus mykiss) was assessed. Lettuces were grown in an aquaponic system with waste from the fish and in a hydroponic system with nutrient solution (Hoagland IImodified) for 21 days. At the end of this period, lettuce of 8 a $12 \mathrm{~cm}$ were obtained. Aquaponic lettuce yield was $6.73 \%$ higher than hydroponic lettuce. Also aquaponic lettuce had lower nitrate concentration than hydroponic lettuce. Lettuces grown in both systems showed no significant differences in the microbiological and functional quality. Rainbow trout in the aquaponic system increased $13.6 \mathrm{~g}$ over $27.1 \pm 0.8 \mathrm{~g}$ initial fresh weight, obtaining a FCR of 0.74 after the experiment. These results indicate that the aquaponic system used is a sustainable alternative for the production of high quality lettuce considering its high yield, lower concentration of nitrates and similar microbiological and functional quality regarding hydroponic systems, while allowing simultaneous fish farming with a good feed conversion ratio.
\end{abstract}

Keywords: Aquaponic; hydroponic; food safety; feed conversion rate; Rainbow trout.

\footnotetext{
${ }^{1}$ Centro de Estudios Postcosecha. Facultad de Ciencias Agronómicas. Universidad de Chile, Chile.

${ }^{2}$ Instituto de Nutrición y Tecnología de Alimentos. Universidad de Chile, Chile.

${ }^{3}$ Departamento de Producción Animal. Facultad de Ciencias Agronómicas. Universidad de Chile. Av. Santa Rosa 11315 (832 0000 ), La Pintana, Santiago, Chile. Email: alcarraz.e@hotmail.com
} 


\section{Introducción}

A nivel mundial la lechuga (Lactuca sativa L.) es el cultivo de mayor importancia económica entre las hortalizas de hojas, debido a la posibilidad de ser cultivado todo el año, bajo diferentes sistemas de producción y a la diversidad de variedades botánicas y cultivares (Suslow et al., 2003). Esta hortaliza se cultiva generalmente en suelos regados principalmente por surcos (Flaño, 2013), estando asociado a un gran consumo de agua y al riesgo de no ser inocuo, en caso de contener aguas contaminadas por bacterias patógenas ej. Escherichia coli 0157:H7, Salmonella o Listeria monocytogenes (Sirsat \& Neal, 2013).

La hidroponía, es un método de cultivo sin el uso del suelo. En su lugar se pueden utilizar sustratos sólidos inertes o medios líquidos sin sustrato. En estos sistemas, todos los nutrientes necesarios para el crecimiento vegetal se obtienen de fertilizantes sintéticos (Tonet et al., 2011 y FAO, 2015). Además, la hidroponía es un sistema más controlado que el cultivo directo en el suelo, que permite tener mayor eficiencia en el uso del agua y fertilizantes, con menores riesgos de plagas y enfermedades. Sin embargo, la completa dependencia de fertilizantes manufacturados hace costosa su implementación por pequeños agricultores (FAO, 2015; Stefanelli et al., 2011 y Hashida et al., 2014). En este sentido, la integración con otros cultivos complementarios, como la producción de peces puede ser una estrategia para enfrentar la necesidad de fertilizantes por las plantas.

La acuicultura es la producción de organismos acuáticos en cautiverio como: peces, moluscos, etc. Las principales categorías de sistemas productivos incluyen los sistemas abiertos (jaulas), estanques, sistemas de recirculación en acuicultura (RAS), etc. (Woynarovich et al., 2011). La acuicultura es una actividad cada vez más importante en la producción mundial de peces, pero presenta problemas de sustentabilidad debido al tratamiento de las aguas residuales ricas en nutrientes, que es un subproducto de la acuicultura (FAO , 2015). Esto se debe en parte, a que una proporción baja de los nutrientes dietarios es retenida por los peces. La mayoría de estos nutrientes son excretados por los peces como fracciones sólidas y disueltas, acumulándose en los sistemas con bajo intercambio de agua y luego, al descomponerse, alteran la calidad del agua (FAO , 2015 y Endut et al., 2010).

Una propuesta de solución a este tipo de problema es el uso de sistemas acuapónicos integrando acuicultura e hidroponía (Figura 1). El objetivo de este sistema es producir peces y hortalizas en un circuito cerrado, donde el uso de fertilizantes sintéticos y la remoción de residuos es prácticamente cero (Rakocy et al. (2006); Guzmán \& Moreno (2012); Nelson \& Pade (2008) y Rakocy, et al. (2006)). En este tipo de sistema los residuos de los peces son convertidos a nutrientes para las plantas por acción de las bacterias nitrificantes. Estas bacterias oxidan el amoníaco a nitrito y este a nitrato, predominando el grupo Nitrosomonas spp. y Nitrobacter spp., respectivamente para cada transformación (Hollyer et al., 2009). Es por esto que este sistema de producción de alimentos ha sido descrito como muy eficiente y ecológico (Sirsat \& Neal, 2013)

Conocer el suministro de nitrato para el crecimiento de las lechugas es importante debido a que una acumulación excesiva en las hojas podría ser peligrosa para la salud de los consumidores ya que están relacionados con agentes cancerígenos como las nitrosaminas (Byrne et al., 2009). Y a la vez se debe tener cuidado con la contaminación microbiológica, en especial en los sistemas acuapónicos, puesto que se utilizan los residuos de los peces como nutrientes que pueden contaminar el agua y las hortalizas (FAO, 2015). Actualmente, los consumidores demandan inocuidad y calidad funcional en los productos hortícolas que adquieren. Así, las propiedades funcionales pasan a formar parte importante de la elección, debido a que las hortalizas son ricas en vitaminas, compuestos antioxidantes, etc. (Scalzo et al., 2005). Estos compuestos son reconocidos por sus efectos beneficiosos en la salud del consumidor (Pérez-Jiménez y Soura-Calixto, 2007) como proteger contra enfermedades crónicas no transmisibles si se consumen regularmente (Base de datos antioxidantes en hortalizas, 2015); Hooper y Cassidy, 2006).

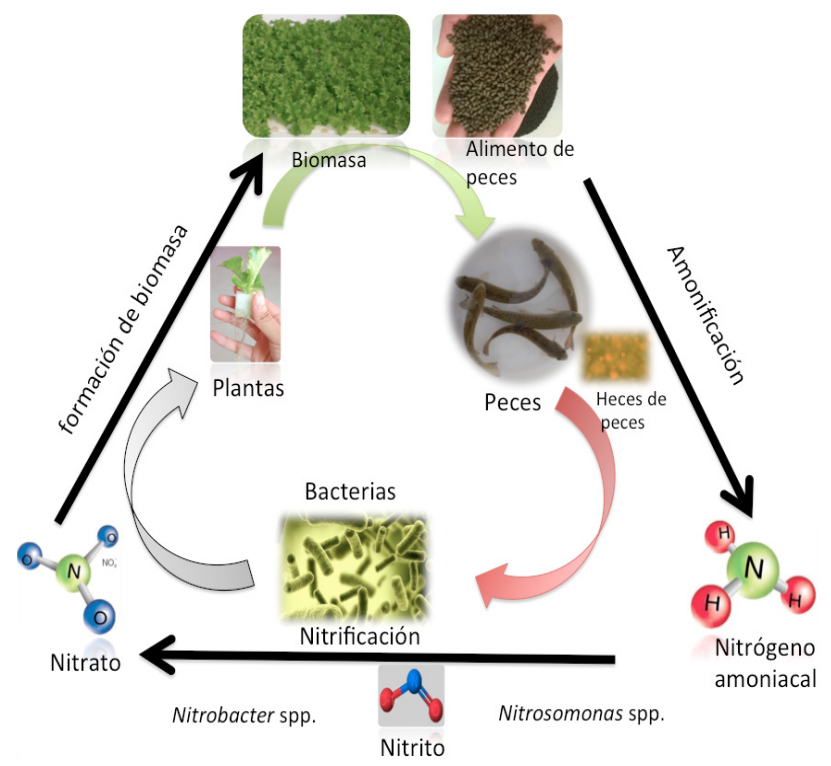

Figura 1. Ciclo acuapónico simbiótico

Finalmente, los sistemas acuapónicos son una buena alternativa para la producción de hortalizas aprovechando los residuos de los peces y optimizando el uso del agua. Sin embargo, existe limitada información sobre la inocuidad de las hortalizas producidas bajo sistemas acuapónicos. Por esta razón, el objetivo de este estudio fue diseñar y probar el funcionamiento de un sistema acuapónico y posteriormente evaluar el rendimiento, concentración de nitrato, la calidad microbiológica y funcional de lechugas (Lactuca sativa L.) cultivadas en este sistema en comparación a otras producidas en un sistema hidropónico convencional. Se estudió también el incremento de masa fresca de las truchas arco iris (Oncorhynchus mykiss) producidas en el sistema acuapónico. 


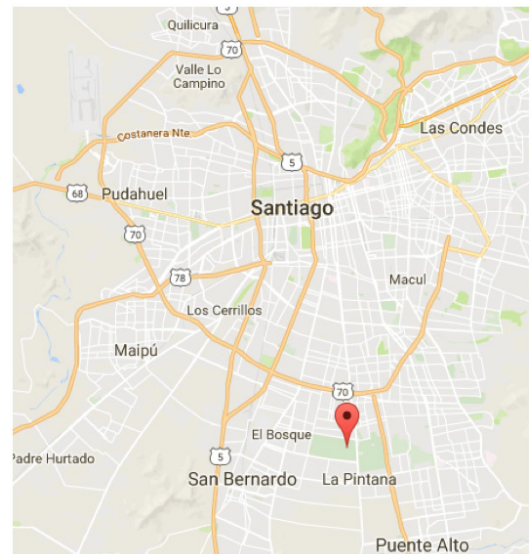

Figura 2. Ubicación geográfica, Universidad de Chile Campus Sur

\section{Sistema acuapónico}

Acuicultura. Los ejemplares de truchas arco iris (Oncorhynchus mykiss) se cultivaron en un estanque rectangular con fondo plano $(0,7 \times 0,4 \times 0,5 \mathrm{~m})$, de $120 \mathrm{~L}$ de capacidad con agua potable desclorada (Figura 3 y 4, A). Las truchas arco iris fueron adquiridas en la piscicultura Río Blanco ubicada en Los Andes, Quinta Región. Se trabajó con 40 ejemplares por estanque y al comienzo cada

\section{Materiales y métodos}

Ubicación del ensayo. El presente estudio se llevó a cabo en el invernadero y los laboratorios del Centro de Estudios Postcosecha (CEPOC) de la Facultad de Ciencias Agronómicas de la Universidad de Chile. Este Centro se encuentra localizado a $33^{\circ} 57^{\circ}$ de latitud sur y $70^{\circ} 60$ de longitud oeste y 627 m.s.n.m, Comuna de La Pintana, Provincia de Santiago, Región Metropolitana, Chile (Figura 2).

Diseño experimental. El diseño fue completamente aleatorizado con dos tratamientos y tres repeticiones por tratamiento para un total de seis unidades experimentales. Los tratamientos correspondieron a un sistema acuapónico y un sistema hidropónico, ambos con un sistema de cultivo de lechugas por la técnica de raíz flotante con una densidad de 70 plantas $/ \mathrm{m}^{2}$.

Manejo de cultivo. Se utilizaron lechugas de la variedad botánica Acephala, cultivar Levistro. Las semillas se sembraron en bandejas alveoladas de 200 unidades, con una mezcla de sustratos lana de roca granulada (Agrolan ${ }^{\circledR}$ Compañía Industrial El Volcán S.A., Chile) y perlita expandida A6 (Harbolite Chile Ltda., Chile) prehidratada en relación volumétrica 1:1, respectivamente. Las semillas se sembraron una por alveolo a $1 \mathrm{~cm}$ de profundidad. Posteriormente, las bandejas se colocaron en una estufa (LabTech Co. Ltda., Korea), a $25{ }^{\circ} \mathrm{C}$ hasta la emisión de la radícula y luego se ubicaron en una mesa de almácigo en el interior del invernadero. Los riegos se realizaron con agua potable hasta que los plantines alcanzaron el estado de desarrollo de cotiledones expandidos. Luego se regaron con solución nutritiva Hoagland II-modificada (Hoagland \& Arnon, 1950), diluida al $50 \%$ manteniendo un $\mathrm{pH}$ entre 5,5 y 6,5 . Cada plantín se trasplantó cuando alcanzó el estado de $3^{\text {ra }}$ a $4^{\text {ta }}$ hoja verdadera (25 días después de la siembra) a los componentes hidropónicos de cada sistema. ejemplar tuvo una masa fresca promedio de $24,4 \pm 0,8 \mathrm{~g}$. Los peces se alimentaron dos veces por día con alimento comercial pelletizado (Ewos ${ }^{\circledR}$ transfer, Chile, que contiene un $48 \%$ de proteína) al $1,44 \%$ de su masa fresca corporal.

Biofiltro. El estanque y la sección del biofiltro (Figura 3 y 4, B) se conectaron a través de una tubería de PVC hidráulico de 2,54 cm de diámetro. Una bomba sumergible (Sicce IDRA, Italia) ubicada en el estanque impulsó el agua $(10 \mathrm{~L} / \mathrm{min})$ desde el estanque de los peces a la sección del biofiltro. El biofiltro estuvo conectado al componente hidropónico (Figura 3 y 4, C) formado por una mesa raíz flotante a través de 8 tuberías de 1,6 cm de diámetro. Estas dos secciones estuvieron a la misma altura separadas a $0,7 \mathrm{~m}$ por sobre el estanque con peces. El biofiltro estuvo constituido por una sección de 0,35 x $0,725 \mathrm{~m}$, donde se colocaron 400 biobolas (Bio-ball Sunsun, China) con un área de superficie total de $20 \mathrm{~m}^{2}$ (Rakocy et al., 2006). El agua pasa por gravedad desde la sección del biofiltro al componente hidropónico.

Componente hidropónico. Las mesas tuvieron dimensiones de $1,05 \times 0,725 \mathrm{~m}$, y como soporte para las plantas se utilizaron planchas de poliestireno expandido de densidad media $\left(20 \mathrm{~kg} / \mathrm{m}^{3}\right)$ y $2,54 \mathrm{~cm}$ de espesor. El agua pasa por gravedad desde la sección hidropónica al sumidero (Figura 3 y 4, D), retornando al estanque de los peces a través de una tubería de PVC hidráulico de 2,54 $\mathrm{cm}$.

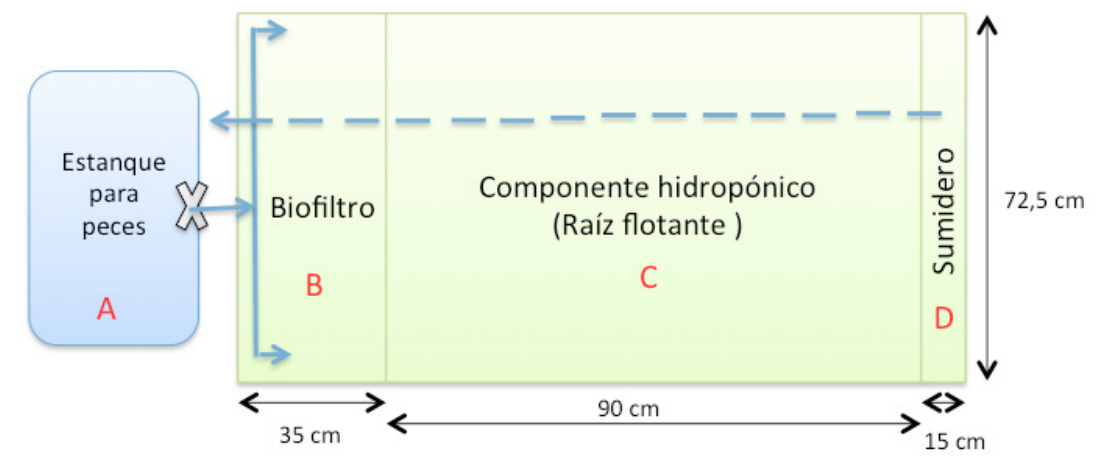

Figura 3. Esquema del sistema acuapónico modificado 


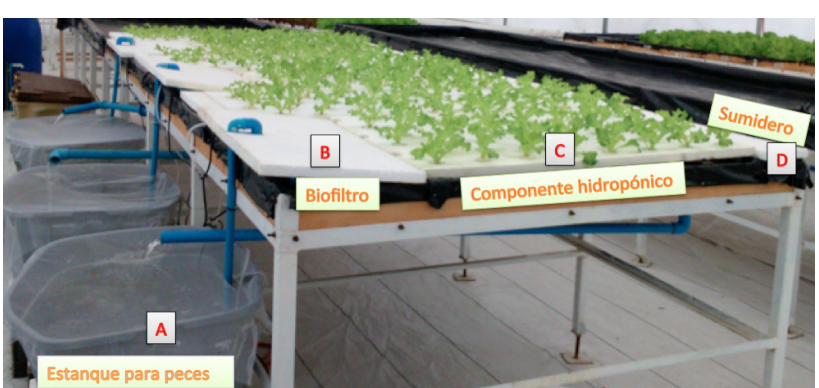

Figura 4. Componentes del sistema acuapónico modificado

Sistema hidropónico.Las mesas tuvieronunas dimensiones de 1,5 x 0,6 m y como soporte para las plantas se utilizaron planchas de poliestireno expandido de densidad media (20 $\mathrm{kg} / \mathrm{m}^{3}$ ) y $2,54 \mathrm{~cm}$ de espesor, perforadas con un orificio de 5 $\mathrm{cm}$ de diámetro. En cada orificio se colocó una planta y en un metro cuadrado 70 plantas siguiendo un diseño Zigzag. Las raíces de las plantas estuvieron en contacto directo con el medio líquido (agua potable y solución nutritiva). Con la ayuda de una bomba de aire (Tetratec APS 300, China) se introdujo oxígeno en cada mesa para oxigenar las raíces de las plantas. La concentración de nitrato en la solución nutritiva, al iniciar el experimento fue de $150 \mathrm{mg} / \mathrm{L}$.

Se cosecharon 35 plantas de lechuga de cada sistema cuando las hojas alcanzaron 8 a $12 \mathrm{~cm}$ de largo (tras 21 días después del trasplante). Las hojas cosechadas se colocaron en 60 bolsas ( 10 bolsas por repetición, de 50 g) de polietileno de baja densidad. Se tomaron muestras al azar para los análisis microbiológicos (tres bolsas) y concentración de nitrato (tres bolsas), el resto de material vegetal (4 bolsas de cada repetición) se mantuvo en una cámara de frío a $5{ }^{\circ} \mathrm{C}$ para las evaluaciones de fenoles totales y capacidad antioxidante.

\section{Determinaciones}

Rendimiento. Para medir el rendimiento foliar de las hojas de lechugas se empleó una balanza portátil (Care CQT202, EE.UU.). Se registró la masa fresca de 35 plantas cosechadas en un área de $0,5 \mathrm{~m}^{2}$ de cada sistema. Los resultados se expresaron como gramos de masa fresca por metro cuadrado (g M.F. $/ \mathrm{m}^{2}$ ).

Concentración de nitrato. Para los análisis, se secaron 3 muestras (por repetición) de $50 \mathrm{~g}$ de lechuga entera de cada sistema, en una estufa a $60{ }^{\circ} \mathrm{C}$ con ventilación forzada durante 72 horas hasta obtener una masa seca constante. Se determinó la concentración de nitratos en las hojas mediante el método del electrodo de ión selectivo de nitrato (Sadzanka et al., 2007). Para determinar la concentración de nitrato se realizaron extracciones en agua donde se mezclaron $0,5 \mathrm{~g}$ de polvo de muestras secas con $25 \mathrm{~mL}$ de agua destilada, y luego se le adicionó una solución de ajuste de fuerza iónica (HI 4013-00) por cada $25 \mathrm{~mL}$ de filtrado. Posteriormente, se introdujo el electrodo selectivo (Hanna, ISA HI 4013-00, Chile), sobre el filtrado de la muestra y se esperó la estabilización de la lectura. La concentración de nitrato se calculó por medio de una curva de calibración sobre la base de estándares de $\mathrm{KNO}_{3}$. Los resultados fueron expresados como miligramos de nitrato por kilogramo de masa fresca (mg/kg M.F.).

Recuento microbiano. El análisis se realizó al momento de la cosecha. Se tomaron tres muestras (por repetición) de $10 \mathrm{~g}$ de lechugas enteras por bolsa y se mezclaron con $90 \mathrm{~mL}$ de agua peptonada $0,1 \%$ estéril (Merck, Alemania) dentro de una bolsa estéril y se homogenizó en un mezclador (IUL, Masticator Classic, España) durante 1 minuto. Se realizaron diluciones seriadas $(1: 10)$ en $9 \mathrm{~mL}$ de agua peptonada $0,1 \%$.

- Aerobios mesófilos (RAM). se realizó una siembra a una profundidad de $1 \mathrm{~mL}$ de la dilución, adecuada en el medio agar de conteo de placas (Merck, Alemania) y se incubaron a $37^{\circ} \mathrm{C}$ durante $48 \mathrm{~h}$.

- Enterobacterias. se realizó una siembra en profundidad, en el medio agar glucosa rojo violeta bilis (VRBD) (Merck, Alemania) y se incubaron a $37^{\circ} \mathrm{C}$ durante $48 \mathrm{~h}$.

- Bacterias psicrófilas. se realizó una siembra en profundidad en el medio agar de conteo de placas (Merck, Alemania) y se incubaron a $5{ }^{\circ} \mathrm{C}$ durante 10 días.

Los recuentos totales se expresaron como el logaritmo de las unidades formadoras de colonias por gramo (log ufc/g).

\section{Concentración de fenoles y capacidad antioxidante}

Extracción de compuestos bioactivos. Para obtener el extracto se utilizó una muestra de $5 \mathrm{~g}$ de lechugas (obtenidas de las bolsas de $50 \mathrm{~g}$ ), se adicionaron $20 \mathrm{~mL}$ de etanol y luego se trituró en Ultraturrax (IKA, T18 Basic, EE.UU.) a $3500 \mathrm{rpm}$ durante $45 \mathrm{~s}$. Se conservó el homogenizado por 24 horas a $5{ }^{\circ} \mathrm{C}$ y posteriormente fue filtrado a través de 4 capas de gasa y centrifugado (Hermle Z 326K, Hermle Labortechnink, Wehngen, Alemania) por 15 min a $4180 g_{n}$ a $4{ }^{\circ} \mathrm{C}$ (Swain \& Hillis, 1959). Las mediciones de fenoles totales y capacidad antioxidante se realizaron con el sobrenadante obtenido.

Fenoles totales. Se llevó a cabo según el método colorimétrico de Singleton y Rossi (1965). A un volumen de $19,2 \mu \mathrm{L}$ de extracto/blanco se le adicionaron $29 \mu \mathrm{L}$ de reactivo Folin-Ciocalteau. Se incubó por 3 minutos a $20^{\circ} \mathrm{C}$ y se le añadió $192 \mu \mathrm{L}$ de $\mathrm{Na}_{2} \mathrm{CO}_{3} 1 \mathrm{~N}$. Pasados 10 minutos, se midió la absorbancia de la muestra a $750 \mathrm{~nm}$ en lector de multiplaca Biochrom (ASYS UVM340, Reino Unido). El contenido de compuestos fenólicos se calculó por medio de una curva de calibración realizada sobre la base de una solución madre de ácido gálico $2,4 \times 10^{-3} \mathrm{M}$. Los resultados fueron expresados como mg equivalente ácido gálico por $100 \mathrm{~g}$ de masa fresca (mg EAG/100g M.F.). 
Capacidad antioxidante por DPPH. La determinación se llevó a cabo según el método de Brand-Williams (BrandWilliams et al., 1995). A $21 \mu \mathrm{L}$ de extracto se añadió 194 $\mu \mathrm{L}$ de solución DPPH. Posteriormente, se les midió la absorbancia a $515 \mathrm{~nm}$, luego de dos horas de incubación a $20{ }^{\circ} \mathrm{C}$ en oscuridad en lector de multiplaca Biochrom. La capacidad antioxidante se calculó por medio de una curva de calibración realizada sobre la base de una solución madre de Trolox 1,6×10-3 M. Los resultados fueron expresados como mg equivalente de Trolox por $100 \mathrm{~g}$ de masa fresca (mg ET/100g M.F.).

Capacidad antioxidante por FRAP. Se realizó según el protocolo propuesto por Benzie \& Strain (1996). Se preparó el reactivo FRAP (buffer acetato $300 \mathrm{mmol} \mathrm{L}^{-1}$ con $\mathrm{pH} 3,5$, solución de cloruro férrico hexohidratado $20 \mathrm{mmol} \mathrm{L}^{-1}$ y 2,4,6-Tripyridyl-s-Triazine (TPTZ) 10 mmol en $\mathrm{HCl} 40 \mathrm{mmol}$ ). Se incubaron $6 \mu \mathrm{L}$ de extracto y $198 \mu \mathrm{L}$ de reactivo FRAP por 30 minutos a $37^{\circ} \mathrm{C}$, para posteriormente medir su absorbancia a $593 \mathrm{~nm}$ en lector multiplaca Biochrom. La capacidad antioxidante se calculó por medio de una curva de calibración realizada sobre la base de una solución madre de Trolox $1,6 \times 10^{-3} \mathrm{M}$. Los resultados fueron expresados como (mg ET/100g M.F.).

Incremento de masa fresca de truchas arco iris. Para medir la masa fresca de los peces se empleó una balanza portátil. Se realizaron muestreos semanales, tomando 15 ejemplares (tres grupos de cinco) al azar de cada estanque. Se calculó el factor de conversión alimenticia $(\mathrm{FCA}=[\mathrm{kg}$ de alimento consumido/(masa fresca final - masa fresca inicial)]). Así también se calculó el incremento de masa fresca porcentual utilizando la fórmula [(masa fresca final*100)/masa fresca inicial)] de las truchas arco iris.

Análisis estadístico. Los resultados obtenidos fueron sometidos a un análisis de varianza (ANDEVA) con un nivel de significancia del 5\%, y en el caso de existir diferencias significativas entre tratamientos, se aplicó el test de comparaciones de rangos múltiples de Tukey utilizando el programa estadístico InfoStat.

\section{Resultados y discusión}

Rendimiento. Se observaron diferencias significativas en el rendimiento de masa fresca de las lechugas cultivadas en ambos sistemas. El rendimiento de las lechugas de hoja fue de $2748 \pm 50 \mathrm{~g}$ por $\mathrm{m}^{2}$ para el sistema acuapónico y de $2575 \pm 50$ g por $\mathrm{m}^{2}$ para el sistema hidropónico (Figura 5).

El rendimiento de las lechugas cultivadas en el sistema acuapónico fue similar a lo reportado por Panatela et al. (2012). Estos autores obtuvieron un rendimiento de 2,71 $\mathrm{kg} / \mathrm{m}^{2}$ (21 días después del trasplante) en lechugas romana cultivadas por la técnica de raíz flotante con residuos de tilapia del Nilo (Oreochromis niloticus L.) mantenidas a una alta densidad de peces $\left(8 \mathrm{~kg} / \mathrm{m}^{3}\right)$. Respecto a otro trabajo realizado por Lennard \& Leonard (2006), el rendimiento obtenido en nuestro estudio fue inferior.

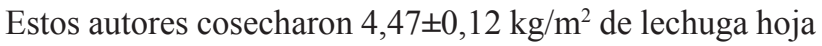
de roble con la técnica raíz flotante empleando residuos de bacalao Murray a una densidad de 40 plantas $/ \mathrm{m}^{2}$. Del mismo modo, Licamele (2009) obtuvo rendimientos de $4,7 \mathrm{~kg} / \mathrm{m}^{2}$ de lechuga cv. Rex (32 plantas $/ \mathrm{m}^{2}$ ) luego de 35 días, en un ensayo de acuaponía con tilapia del Nilo (Oreochromis niloticus L.), ambos a una densidad de peces de $5 \mathrm{~kg} / \mathrm{m}^{3}$. El mayor rendimiento en estos estudios se debería a que el bacalao Murray y la tilapia del Nilo fueron producidas a temperaturas de 20 a $25^{\circ} \mathrm{C}$, rango óptimo para estos peces, para las bacterias nitrificantes y las lechugas (FAO, 2015). En otros estudios se menciona que a menudo el rendimiento de las hortalizas de hoja en acuaponía es similar o incluso superior a los sistemas hidropónicos (Licamele, 2009; Graber \& Junge, 2009 y Savidov, 2005). En ensayos realizados bajo condiciones de invernadero, se reportó que los sistemas de acuaponía maduros (sistemas de 4 a 6 meses en funcionamiento) dieron un crecimiento acelerado de diversas especies vegetales y rendimientos más altos que la hidroponía para tomate y pepino (Savidov , 2005).

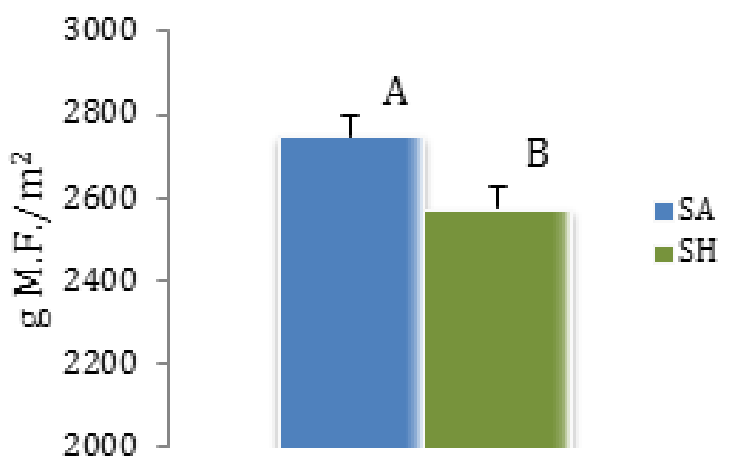

Figura 5. Rendimiento (g M.F. $/ \mathrm{m}^{2}$ ) en las lechugas cultivadas en los sistemas acuapónico e hidropónico. Las barras representan la media $(n=3) \pm E S$. Letras distintas indican diferencias significativas entre los sistemas de cultivo acuapónico e hidropónico $(\mathrm{P} \leq 0,05)$.

Concentración de nitrato en las hojas de lechuga: En ambos sistemas de cultivo se observaron diferencias significativas en la concentración de nitrato. La concentración de nitrato para hojas de lechuga acuapónica e hidropónica fue de $1079 \pm 32$ y $1229 \pm 32 \mathrm{mg} / \mathrm{kg}$ M.F. respectivamente (Figura 6), mostrando una menor concentración de nitrato en las lechugas acuapónicas.

La concentración de nitrato en lechugas cultivadas por el sistema acuapónico fue mayor a lo obtenido por Blidariu et al. (2013) que registraron $810 \mathrm{mg} / \mathrm{kg}$ M.F. en lechugas var. Capitata cv. Española cultivada con residuos de lucioperca (Sander lucioperca). La concentración de nitrato en las hojas de lechugas hidropónicas fue superior a $1087,2 \pm 458,1 \mathrm{mg} / \mathrm{kg}$ M.F. reportado por Lastra et al. (2009), para lechugas var. Acephala cultivares Grand Rapids y Brisa y var. Capitata cultivares Divina y Prima cultivadas en un sistema raíz flotante. Es posible que la 
mayor concentración de nitratos en lechugas cultivadas por el sistema hidropónico observado en este estudio se explique por la mayor disponibilidad de nitrato en la solución nutritiva al comienzo que fue de $150 \mathrm{mg} / \mathrm{L}$. En cambio, en el sistema acuapónico, se mantuvo una concentración promedio de 14,9 $\mathrm{mg} / \mathrm{L}$. En este sentido, el uso de fertilización nitrogenada como herramienta para obtener rendimientos altos podría exceder las dosis adecuadas, favoreciendo una acumulación de nitratos elevada en los tejidos (Stefanelli et al., 2011; Lastra et al., 2009 y Santamaria, 2006).

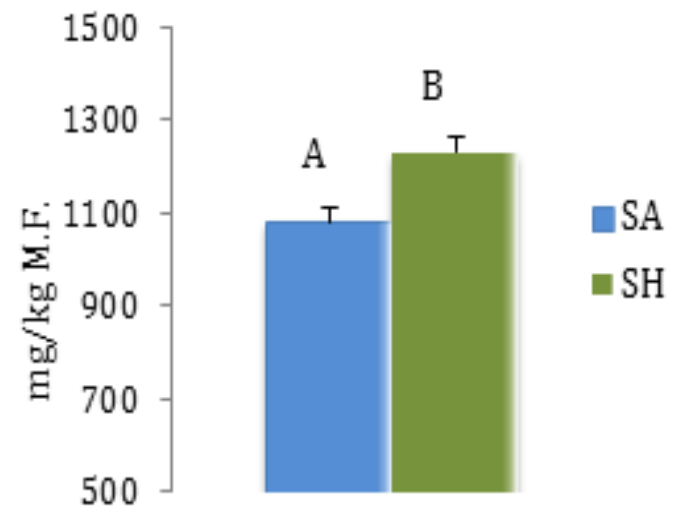

Figura 6. Concentración de nitrato (mg/kg M.F.) en hojas de las lechugas cultivadas en los sistemas acuapónico e hidropónico. Las barras representan la media $(n=3) \pm E S$. Letras distintas indican diferencias significativas entre los sistemas de cultivo acuapónico e hidropónico $(\mathrm{P} \leq 0,05)$

Así también, el horario de cosecha es un factor fundamental en la acumulación de nitratos, ya que la nitrato reductasa (NR) que degrada los nitratos, se activa en presencia de radiación fotosintéticamente activa (PAR) (Raigon et al., 2006). En este estudio, las lechugas de ambos sistemas se cosecharon a las $12 \mathrm{~h}$. Contreras (2014) observó una menor acumulación de nitratos en hojas de acelga (Beta vulgaris L. var. Cicla) cosechadas a las 12 y $21 \mathrm{~h}$, respecto a las hojas cosechadas a las $8 \mathrm{~h}$ del día. Además, los nitratos continúan acumulándose en las hojas mientras aumenta la edad de la planta, por lo que las hojas exteriores tienen mayor cantidad frente a las hojas internas (Anjana et al., 2006). Otro aspecto a considerar es que la actividad de la NR tiende a disminuir y el nitrógeno a perder movilidad dentro del floema con la edad del cultivo, por lo que los nitratos pueden acumularse (Marschner, 1995). Contreras Contreras (2014) también observó mayor acumulación de nitratos en el tallo y la nervadura central frente a la lámina de las hojas de acelgas. Por otra parte, se debe considerar que existe un componente genético entre especies y cultivares, que varían en su acumulación de nitrato en las hojas (Lastra et al., 2009). Si bien en este estudio las lechugas hidropónicas obtuvieron una mayor concentración de nitrato, esta concentración no superó el límite máximo establecido por la legislación de la Comisión Europea (European Commission Commission
Regulation, 2011), que establece como máximo 4000 $\mathrm{mg}$ de nitratos por $\mathrm{kg}$ M.F. para lechuga de invernadero cosechadas en invierno.

Recuentos microbiológicos. En ambos sistemas de cultivo no se observaron diferencias significativas en los recuentos microbiológicos al momento de la cosecha. Los recuentos promedio fueron 3,2 $\pm 0,1 \log \mathrm{UFC} / \mathrm{g}$ para aerobios mesófilos $1,0 \pm 0,5 \log \mathrm{UFC} / \mathrm{g}$ para enterobacterias y 2,3 $\pm 0,3 \log \mathrm{UFC} / \mathrm{g}$ para bacterias psicrófilas en hojas de lechugas cultivas por el sistema acuapónico e hidropónico (Figura 7).

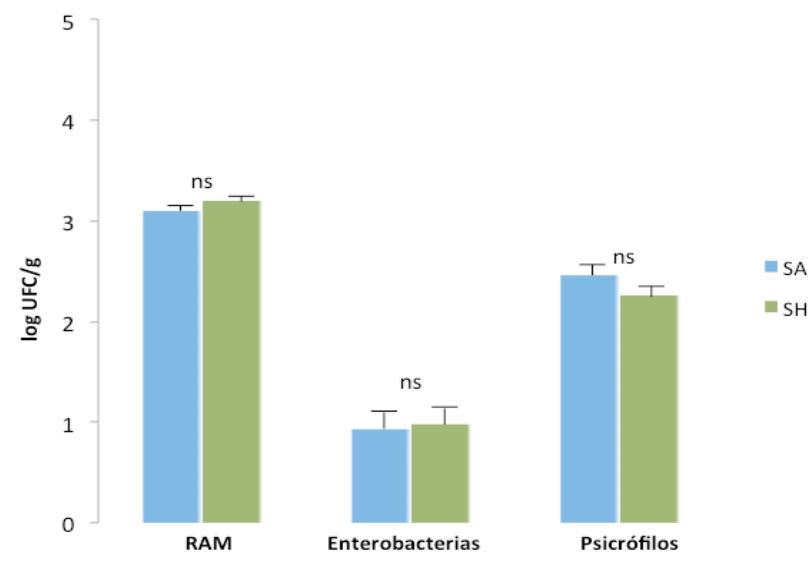

Figura 7. Recuento de aerobios mesófilos (RAM), enterobacterias y bacterias psicrófilas (log UFC/g) al momento de la cosecha en hojas de lechuga cultivadas en ambos sistemas. Las barras representan la media $(n=3) \pm E S$. Ns, no significativo $(\mathrm{P}>0,05)$

Mesófilos. El recuento de bacterias aerobias mesófilas (RAM) en hojas fue similar al valor reportado por Sirsat \& Neal (2013), quienes encontraron 3,2 log UFC/g para lechuga romana cultivada por acuaponía en invernadero. Mientras que Selma et al. (2012) y Scuderi et al. (2011) reportaron recuentos de 4,0 y 6,0 log UFC/g para lechugas cultivadas en un sistema hidropónico NGS y raíz flotante, respectivamente.

Enterobacterias. El recuento de enterobacterias fue menor a 2,3 log UFC/g al reportado por Scuderi et al. (2011) en un estudio similar.

Psicrófilas. El recuento de las bacterias psicrófilas en hojas fue menor al valor reportado por Orellana (2011), quien encontró 4,9 $\log \mathrm{UFC} / \mathrm{g}$ reportado para hojas de rúcula cultivada por hidroponía en invernadero. Es importante tener bajos recuentos de las bacterias psicrófilas, ya que al almacenarse las hortalizas en refrigeración podrían multiplicarse rápidamente y afectar su calidad (Selma et al., 2012) .

Los bajos recuentos microbiológicos en las hojas de lechuga al momento de la cosecha podrían deberse a que en 
los sistemas de cultivo se utilizó agua potable como fuente de agua para la puesta en marcha y la recarga del sistema (Rakocy et al., 2006). Además, las hojas de las lechugas nunca estuvieron en contacto con el agua de peces en el sistema acuapónico (Erickson, 2012) ni con la solución nutritiva en el sistema hidropónico.

La fuente de agua utilizada en los sistemas acuapónicos tiene una incidencia significativa en la calidad de los productos finales, ya sean peces o plantas (Chalmers, 2004). Una de las bacterias más estudiadas es la Escherichia coli, la cual se encuentra en los intestinos de animales de sangre caliente como los cerdos, aves, vacunos, etc. Para que esta bacteria esté presente en los sistemas acuapónicos debería provenir de aves o de los mismos operarios, si en la granja no se aplican las buenas prácticas agrícolas (Fox et al., 2012). Se considera que la temperatura corporal promedio de los animales poiquilotermos (cuya temperatura corporal varía según la temperatura del ambiente) como los peces, es baja para favorecer la proliferación óptima de la mayoría de las bacterias entéricas que pueden infectar a los humanos (Sugita et al., 1996). La preocupación por la calidad microbiológica de la lechuga es cada vez más importante, debido a que esta hortaliza se consume cruda, sin ningún tratamiento letal para los microorganismos y puede afectar la salud del consumidor (Franz et al., 2008). Un mayor riesgo de contaminación y un posterior aumento de las poblaciones microbianas ocurre cuando las superficies de las lechugas están en contacto directo con el suelo (Fallovo et al., 2009), a diferencia de los sistemas acuapónico e hidropónico cultivados por las técnicas raíz flotante o NFT, donde solo las raíces de las plantas están en contacto con la solución nutritiva y no la parte aérea comestible (FAO, 2015). Por estas razones, en este estudio las lechugas cultivadas en ambos sistemas presentaron recuentos microbiológicos inferiores a lo establecido por el Reglamento Sanitario de Alimentos para frutas y otros vegetales pre-elaborados listos para el consumo (Ministerio de Salud Pública de Chile, 2014). Este reglamento establece un límite máximo para RAM y enterobacterias de 6,69 y 4,69 $\log \mathrm{UFC} / \mathrm{g}$, respectivamente.

Fenoles totales y capacidad antioxidante: El contenido promedio de fenoles totales de $153 \mathrm{mg}$ EAG/100 g M.F. (Tabla 1) fue superior a los valores reportados por Llorach et al. (2008) quienes registraron 18,2; 63,5 y $125,5 \mathrm{mg}$ EAG/100 g M.F. para lechugas iceberg, romana y continental, respectivamente. El contenido de fenoles fue similar a la lechuga española con $164 \mathrm{mg}$ EAG/100 g M.F. e inferior al de las lechugas tipo francesa con 278 mg EAG/100 g M.F. (Base de datos antioxidantes en hortalizas, 2015), hoja de roble rojo con $322 \mathrm{mg} \mathrm{EAG} / 100 \mathrm{~g}$ M.F. y Lollo roso con $571 \mathrm{mg}$ EAG/100 g M.F. (Llorach et al., 2008).
La capacidad antioxidante promedio determinada por los métodos DPPH y FRAP fue de 157 y 283 mg ET/100 g M.F. (Tabla 1), inferior a los valores reportados por Llorach et al. (2008) quienes registraron 244,1 mg ET/100 g M.F. por DPPH y $323,4 \mathrm{mg}$ ET/100 g M.F. por FRAP para la lechuga $\mathrm{cv}$. continental. La capacidad antioxidante por ambos métodos fue inferior al registrado en lechugas de coloración roja (hoja de roble, Lollo roso) que superaron los $600 \mathrm{mg}$ ET/100 g M.F. para DPPH y FRAP (Llorach et al., 2008). Sin embargo, la calidad funcional (fenoles totales y capacidad antioxidante) varía considerablemente según variedades botánicas, cultivares, prácticas culturales, tipo de procesamiento y con las condiciones de almacenamiento [Llorach et al. (2008) y Nicolle et al. (2004)]. En general, las lechugas rojas muestran un mayor contenido de compuestos funcionales respecto a lechugas verdes [Selma et al. (2012) y Rivera (2014)].

Selma et al. (2012) evaluaron la calidad funcional de lechugas cultivadas en el suelo e hidroponía obteniendo en ambos similares contenidos de fenoles y vitamina C. Una situación similar ocurrió en este estudio donde los métodos de cultivo no influyeron en estos parámetros.

Tabla 1. Fenoles (mg EAG/100 g M.F.) y capacidad antioxidante por los métodos DPPH y FRAP (mg ET/100 g M.F.) en las lechugas acuapónicas e hidropónicas. Los valores representan la media $(n=3) \pm E S$. NS, no significativo $(\mathrm{P}>0,05)$

\begin{tabular}{cccc}
\hline \multirow{2}{*}{ Sistemas } & Fenoles totales & \multicolumn{2}{c}{$\begin{array}{c}\text { Capacidad antioxidante mg } \\
\text { ET/100 g M.F. }\end{array}$} \\
\cline { 3 - 4 } & mg EAG/100 g M.F. & DPPH & FRAP \\
\hline Acuapónico & $156,6 \pm 29,4 \mathrm{~ns}$ & $181,5 \pm 43,9 \mathrm{~ns}$ & $255,5 \pm 16,5 \mathrm{~ns}$ \\
Hidropónico & $150,3 \pm 70,3 \mathrm{~ns}$ & $132,7 \pm 21,3 \mathrm{~ns}$ & $309,8 \pm 42,1 \mathrm{~ns}$ \\
\hline
\end{tabular}

Incremento de masa fresca de truchas arco iris: En la Tabla 2 se observa el incremento de masa fresca y el factor de conversión alimenticia (FCA) de truchas arco iris cultivadas en el sistema acuapónico. La masa fresca promedio al inicio del experimento fue de $27,1 \pm 0,83 \mathrm{~g}$ por pez. Luego de tres semanas los peces incrementaron su masa fresca en $13,6 \pm 1,5 \mathrm{~g}$ con una tasa de alimentación del 1,44 \% de su masa fresca corporal por día. El factor de conversión alimentaria de los peces fue de 0,74 .

Tabla 2. Incremento de masa fresca y factor de conversión alimenticia (FCA) e incremento de masa fresca semanal de 40 peces del sistema acuapónico. Los valores de biomasa fresca (número de peces x masa fresca $(\mathrm{g})$ de peces) son la media $(\mathrm{n}=3) \pm \mathrm{ES}$

\begin{tabular}{|c|c|c|c|c|c|c|}
\hline \multirow{2}{*}{ SA } & \multicolumn{4}{|c|}{ Semanas de cultivo } & \multirow{2}{*}{$\begin{array}{l}\text { Alimento } \\
\text { consumido }\end{array}$} & \multirow{2}{*}{ FCA } \\
\hline & 0 & 1 & 2 & 3 & & \\
\hline $\begin{array}{l}\text { Biomasa } \\
\text { acumulada (g) }\end{array}$ & $1085 \pm 33$ & $1294 \pm 53$ & $1453 \pm 52$ & $1614 \pm 78$ & $393 \pm 4$ & 0,74 \\
\hline $\begin{array}{l}\text { Incremento de } \\
\text { masa fresca }(\%)\end{array}$ & - & 19 & 12 & 11 & & \\
\hline
\end{tabular}


Para cualquier sistema de acuicultura, la sobrevivencia de los peces y los parámetros de crecimiento son de suma importancia (Lennard \& Leonard ,2006). Waynarovich et al. (2011) indican una mortalidad normal del $5 \%$ (en un periodo de 4 a 6,5 meses de cultivo) para trucha arco iris con una masa fresca superior a $25 \mathrm{~g}$ dentro de un sistema acuícola tradicional. En el presente estudio, no hubo mortalidad de truchas arco iris en ninguna de las repeticiones para el ensayo de 21 días. En términos de eficiencia de conversión alimenticia, los valores FCA obtenidos en el presente estudio (Tabla 2) se encuentran dentro del rango descrito por Merino y Von-Brand (2015). Este autor indicó como adecuado un FCA $<1$ para ejemplares de trucha arco iris con una masa fresca menor a $100 \mathrm{~g}$ y alimentados con pellets con un $42 \%$ de proteína cultivadas en un sistema acuapónico comercial. En otro estudio, Lennard \& Leonard (2006) y Palm et al. (2014) obtuvieron en sistemas acuapónicos un FCA de 0,85 y 0,93 para bacalao Murray (Maccullochella peelii peelii) y tilapia del Nilo (Oreochromis niloticus), respectivamente, ambos asociados al cultivo con lechuga. El crecimiento y FCA de los peces depende directamente de la calidad y cantidad del alimento y la calidad de agua durante el cultivo (Palm et $a l ., 2014)$. El alimento que se utilizó en el presente estudio contiene un $48 \%$ de proteína y los diferentes parámetros de calidad de agua estuvieron dentro del rango recomendado para trucha arco iris (Endut et al., 2010).

A la vista de los resultados y considerando otras investigaciones, se puede afirmar que existe un efecto sinérgico entre los dos subsistemas productivos (hidropónico y acuícola), obteniéndose en ambos, buenos rendimientos en hortalizas y peces. Se debe tener en cuenta que este estudio tuvo una duración de 21 días, con el propósito principal de diseñar y probar un sistema acuapónico que alcance el equilibrio entre los subsistemas y que asegure la producción de lechugas frescas, nutritivas/ funcionales e inocuas junto a la de peces vivos.

\section{Conclusiones}

Las lechugas cultivadas por el sistema acuapónico obtuvienen un mayor rendimiento $y$ una menor concentración de nitratos en las hojas frente a las lechugas cultivadas por el sistema hidropónico.

Las lechugas producidas en ambos sistemas tuvieron similar calidad microbiológica y funcional resultando aptas para el consumo humano.

Los peces producidos en el sistema acuapónico incrementan la masa fresca y presentan un buen factor de conversión alimentaria.

Por lo que el sistema acuapónico es una tecnología eficiente para producir truchas arco iris y lechugas frescas de calidad, especialmente en las poblaciones donde el agua y/o fertilizantes son recursos limitados.

\section{Agradecimientos}

Al Proyecto FIC 30137762-0 de la Región de Coquimbo
(Chile) "Diversificación de la industria alimentaria de la Región de Coquimbo a través del desarrollo sustentable de un proceso productivo en acuaponía", Brianna, Gadiel y a los integrantes del CEPOC.

\section{Literatura citada}

Anjana, S.; Umar, S. \& Iqbal, M. 2006. Nitrate accumulation in plants, factors affecting the process and human health implications. A review. Agron 27: 45-57.

Base de datos antioxidantes en hortalizas. 2015. Santiago: Portal Antioxidantes Instituto de Nutrición y Tecnología de Alimentos de la Universidad de Chile. Recuperado de: http://www.portalantioxidantes.com/base-de-datosde-antioxidantes-de-hortalizas/

Benzie, I.F. \& Strain, J.J. 1996. The ferric reducing ability of plasma (FRAP) as a measure of "antioxidant power": The FRAP assay. Analytic Biochemistry 239: 70-76.

Blidariu, F.; Radulov, I.; Lalescu, D.; Drasovean, A. \& Grozea, A. 2013. Evaluation of nitrate level in green lettuce conventional grown under natural conditions and aquaponic system. Animal Science and Biotechnologies 46 (1): 244-250.

Brand-Williams, W.; Cuverlier, ME.; Berset, C. 1995. Use of a free radical method to evaluate antioxidant activity. Food Science and Technology 16: 25-30.

Byrne, C.; Maher, M.; Hennerty, M.; Mahon, M. \& Walshe, P. 2009. Reducing the nitrate content of protected lettuce. Recuperado de: http:/www.teagasc.ie/research/ reports/horticulture/4561/eopr-4561.pdf

Chalmers, GA. 2004. Aquaponics and food safety (Thesis). Canada.

Contreras, MA. 2014. Efecto de la concentración de $N$ en la solución nutritiva y del horario de cosecha sobre el contenido de nitrato en hojas de dos cultivares de acelga del tipo baby, bajo sistema hidropónico (Tesis); Universidad de Chile; Chile.

Endut ,A.; Jusoh, A.; Ali, N.; Wan, WB.; Hassan, A. 2010. study on the optimal hydraulic loading rate and plant ratios in recirculation aquaponic system. Bioresource Technology 101: 1511-1517.

Erickson, MC. 2012. Internalization of Fresh Produce by Foodborne Pathogens. Annual Review of Food Science and Technology 3: 283-310.

European Commission Commission Regulation [EU] 2011. No 1258/2011 of 2 December 2011 amending Regulation (EC) No. 1881/2006 as regards maximum levels for nitrates in foodstuffs. Off. J. Eur. Union.2011;L320:15-17.

FAO. 2015. Small-scale aquaponic food production. Fisheries and Aquaculture Technical Paper. Recuperado: http:/www.fao.org/publications/card/en/c/90bb6bfe1ac3-4280-857e-1c5a20404b38/.

Fallovo, C.; Rouphael, Y.; Rea, E.; Battistelli, A. \& Colla G. 2009. Nutrient solution concentration and growing season affect yield and quality of Latuca sativa L. var. 
acephala in floating raft culture. J. Sci. Food Agric. 89: 1682-1689.

Flaño, A. 2013. Mercado nacional de las hortalizas frescas. ODEPA, Chile. Mayo, 30 p.

Fox, B.; Tamaru, C.; Hollyer, J.; Castro, L.; Fonseca, J.; Jay-Russell, M. et al., 2012. A preliminary study of microbial water quality related to food safety in recirculating aquaponic fish and vegetable production systems. Food Safety and Technology FST-51.

Franz, E.; Semenov, AV.; Van Bruggen, AH. 2008 Modelling the contamination of lettuce with Escherichia coli O157:H7 from manure-amended soil and the effect of intervention strategies. J. Appl. Microbiol. 105(5): 1569-1584.

Graber, A. \& Junge, R. 2009. Aquaponic Systems: Nutrient recycling from fish wastewater by vegetable production. Desalination. 246: 147-156.

Guzmán, RL. \& Moreno, LA. 2012. La acuaponía una estrategia interdisciplinaria generadora de conocimientos en la escuela normal de Gachetá. Escuela Normal Superior de Gachetá. Recuperado de: http://escuelanormalsuperiordegacheta.files.wordpress. com/2011/05/articulo-normal-gacheta.pdf

Hashida, S.; Kitazaki, K.; Shoji, K.; Goto, F. y Yoshihara, T. 2014. Influence of nitrogen limitation and longterm use of rockwool on nitrous oxide emissions in hydroponic systems. Journal of Horticulture 1(3): 715 725.

Hoagland, D. \& Arnon, D. 1950. The water-culture method for growing plants whitout soil. California Agricultural Experimental Station Bulletin. 1950; 347.

Hollyer, J.; Tamaru, C.; Riggs, A.; Klinger-Bowen, R.; Howerton, R.; Okimoto, L.; Castro, L. et al., 2009. on-farm food safety: aquaponics. Food Safety and Technology 38.

Hooper, L. \& Cassidy, A. 2006. A review of the health care potential of bioactive compounds. Journal of the Science of Food and Agriculture 86(12): 1805-1813.

Lastra, O.; Tapia, ML.; Razeto, B. \& Rojas, M. 2009. Response of hydroponic lettuce cultivars to different treatments of nitrogen: growth and foliar nitrate content. Idesia 27: 83-89.

Lennard, WA. \& Leonard, BV. A. 2006. comparison of three different hydroponic sub-systems (gravel bed, floating and nutrient film technique) in an Aquaponic test system. Aquacult Int. 14: 539-550.

Licamele, J. 2009. Biomass production and nutrient dynamics in an aquaponics system (PhD Dissertation) Univerisity of Arizona, EEEUU.

Llorach, R.; Martínez-Sánchez, A.; Tomás-Barberán, FA.; Gil, MI. \& Ferreres, F. 2008. Characterisation of polyphenols and antioxidant properties of five lettuce varieties and escarole. Food Chemistry 108: 1028-1038.

Marschner, H. 1995. Mineral nutrition of higher plants. Academic press, London. England. 224:312.
Merino, G. y Von-Brand E. Acuiponia con truchas en zonas aridas - Valle del Elqui. Universidad Autonoma Baja California Sur; 2015. Presentación.

Ministerio de Salud Pública de Chile. 2014. Reglamento sanitario de los alimentos. Diario oficial 13 de mayo 1997. Decreto supremo 977. Actualizado en Septiembre del 2014. Depto. de Asesoría Jurídica. Santiago. 181 p.

Nelson, LR. \& Pade, JS. 2008. Aquaponics equipment equipment the bio filter. Nelson and Pade, The Most Trusted name in Aquaponics Recuperado de: http:// aquaponics.com/media/docs/articles/AquaponicEquipment-The-BioFilter.pdf

Nicolle, C.; Cardinault, N.; Gueux, E.; Jaffrelo, L.; Rock, E,; Mazur, A. et al., 2004. Health effect of vegetablebased diet: Lettuce consumption improves cholesterol metabolism and antioxidant status in the rat. Clinical Nutrition 23(4): 605 - 614.

Orellana, MA. 2011. Efecto de distintos sanitizantes sobre la carga microbiana y calidad funcional en rúcula (Eruca sativa Mill) almacenadas bajo refrigeración (Tesis). Universidad de Chile, Chile.

Palm, HW.; Bissa, K. \& Knaus, U. 2014. Significant factors affecting the economic sustainability of closed aquaponic systems. Part II: fish and plant growth. Journal of the Bioflux Society 7(3): 162-175.

Pantanella, E.; Cardarelli, M. \& Colla, G. 2012. Aquaponics vs. hydroponics: production and quality of lettuce crop. International Society for Horticultural Science. 927.

Pérez-Jiménez, J. y Soura-Calixto, F. 2007. Metodología para la evaluación de capacidad antioxidante en frutas y hortalizas. 8: 1150-1160.

Raigon, MD.; García-Martínez, MD.; Guerrero, C. y Esteve, P. 2006. Actividad de la nitrato reductasa y su relación con los factores productivos en lechuga. VII Congreso SEAE Zaragoza. 157: 1-11.

Rakocy, J.; Masser, M.; Losordo, T. 2006. Recirculating aquaculture tank production systems: aquaponicsintegrating fish and plant culture. Southern Regional Aquaculture Center. 2006 Nov; 454.

Rivera, LA. 2014. Efecto de la radiación $U V-B$ en la capacidad antioxidante de lechugas (Lactuca sativa L.) "baby" hidropónicas (Tesis). Universidad de Chile, Chile.

Santamaria, P. 2006. Nitrate in vegetables: toxicity, content, intake and EC regulation. J. Sci. food Agric. 86: 10-17.

Scalzo, J.; Politi, A.; Pellegrini, N.; Mezzetti, B. y Battino M. 2005. Plant genotype affects total antioxidant capacity and phenolic contents in fruit. Nutrition 21:207-213.

Savidov, N. 2005. Evaluation and development of aquaponics production and product market capabilities in Alberta. Phase II. Final Report - Project \#200467905621. 2005 Dec 20; 57p.

Scuderi, D.; Restuccia, C.; Chisari, M.; Barbagallo, RN.; Caggia, C. \& Giuffrida, F. 2011. Salinity of nutrient 
solution influences the shelf-life of fresh-cut lettuce grown in floating system. Postharvest Biology and Technology 59: 132-137.

Sirsat, SA. \& Neal, JA. 2013. Microbial profile of soilfree versus in-soil grown lettuce and intervention methodologies to combat pathogen surrogates and spoilage microorganisms on lettuce. Foods 2(4):488498.

Selma, MV.; Luna, MC.; Martínez-Sánchez, A.; Tudela, JA.; Beltrán, D.; Baixauli, C. \& Gil, MI. 2012. Sensory quality, bioactive constituents and microbiological quality of green and red fresh-cut lettuces (Lactuca sativa L.) are influenced by soil and soilless agricultural production systems. Postharvest Biology and Technology 63(1): 16-24

Singleton, VL. \& Rossi, JA. 1965. Colorimetry of total phenolics with phosphomolybdic-phosphotungstic acid reagents. American Journal of Enology and Viticulture. 16: $144-157$.

Stefanelli, D.; Winkler, S. y Jones, R. 2011. Reduced nitrogen availability during growth improves quality in red oak lettuce leaves by minimizing nitrate content, and increasing antioxidant capacity and leaf mineral content. Agricultural Sciences 2(4): 477-486.

Sugita, H.; Shibuya, K.; Shimooka, H.; Deguchi, Y. 1996. Antibacterial abilities of intestinal bacteria in freshwater cultured fish. Aquaculture 145 (1-4): 195-203.

Suslow, TV.; Oria, MP.; Beuchat, LR. 2003. Production practices as risks factors in microbial food safety of fresh and fresh-cut produce. Food Science and Food Safety 2: 38-77.

Swain, T. \& Hillis, W.E. 1959. The phenolic constituents of Prunus domestica. I. -The quantitative analysis of phenolic constituents. Journal of the Science of Food and Agriculture 10: 63-68.

Tonet, A.; Ribeiro, A.; Bagatin, A.; Quenehenn, A.; Suzuki, C. 2011. Análise microbiológica da água e da alface (Lactuca sativa L.) cultivada em sistema aquapônico, hidropônico e em solo. Revista Brasileira de Pesquisa em Alimentos 2 (2): 83-88.

Woynarovich, A.; Hoitsy, G.; Poulsen, M.T. 2011. Smallscale rainbow trout farming. Fisheries and aquaculture technical paper 561, 81 . 